\title{
Analysis of pollutant emissions and fuel consumption for the use of a multi-storey carpark
}

ARTICLE INFO

Received: 27 July 2021

Revised: 30 July 2021

Accepted: 30 August 2021

Available online: 1 September 2021
In Poland, the number of vehicles owned per capita is systematically increasing. There is also a noticeable increase in traffic in large urban agglomerations. This creates a number of problems, such as difficulties in finding a parking spot. Then it becomes necessary to search for a long time to stop, which is correlated with higher emission of harmful substances and energy consumption. The aim of the work is a multi-criteria analysis of the selection of a parking spot at a shopping center focused on travel times, pollutant emissions and fuel consumption. In addition, consideration was given to the selection of the optimal parking spot. The tests were carried out in Real Driving Conditions similar to Real Driving Emissions testing. The procedure, currently used as an extension of the type-approval tests, reflects the actual exhaust emissions from vehicles more accurately than tests under laboratory conditions. Specialized PEMS (Portable Emissions Measurement System) apparatus was used for the measurements.

Key words: real driving emissions, exhaust emissions, fuel consumption, energy consumption, parking

This is an open access article under the CC BY license (http://creativecommons.org/licenses/BY/4.0/)

\section{Introduction}

Transport has a significant impact on the natural environment through the emission of harmful substances. The consequence of its negative impact include climate changes, which leads to, among others, melting glaciers, shrinking Arctic sea ice sheets, rising sea levels, changing the structure of precipitation and intensification of extreme weather events [1]. To reduce emissions, the European Union has set a climate and energy plan that covers the period up to 2050 . One idea is to reduce transport emissions by $60 \%$ compared to 1990 . As passenger vehicles account for $61 \%$ of all $\mathrm{CO}_{2}$ emissions from road transport, steps have been taken to reduce their environmental impact (Fig. 1). More and more restrictive requirements are introduced, and manufacturers, in order to obtain approval, must meet the conditions provided for in the emission standards [2]. In addition, the new regulations include tests under real driving conditions, which better reflect pollutant emissions and complement laboratory tests [3].

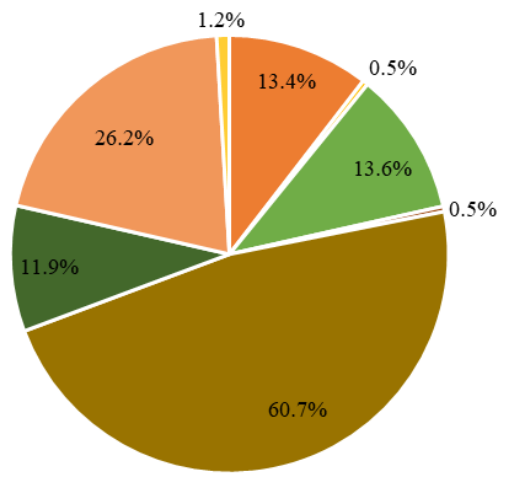

- civil aviation

"rail

- water transport

- other

- passenger cars

- light duty vehicles

" heavy duty vehicles

- motorcycles

Fig. 1. Share of $\mathrm{CO}_{2}$ emission of each transport type [3]

Poland is one of the most motorized countries in Europe. There are 617 passenger vehicles per 1,000 people (as of 2018) [4], which is associated with an increase in traffic, especially in larger cities such as Poznań (Table 1). According to the results presented by TomTom International BV, the volume of traffic in Poznan is systematically increasing. In 2019, a 5\% increase in traffic was recorded as compared to the previous year [5]. This creates a number of problems, incl. difficulty in finding a parking space. Having a large number of vehicles makes it very difficult to park near your destination. This mainly applies to places visited by a large number of people, such as shopping malls or the city center.

Table 1. Countries in the European Union with the highest number of passenger vehicles per 1,000 inhabitants [4]

\begin{tabular}{|c|c|}
\hline Country & $\begin{array}{c}\text { Number of passenger cars per 1000 inhabit- } \\
\text { ants in 2018 }\end{array}$ \\
\hline Luxembourg & 676 \\
\hline Italy & 646 \\
\hline Cyprus & 629 \\
\hline Finland & 629 \\
\hline Poland & 617 \\
\hline Malta & 608 \\
\hline Germany & 567 \\
\hline Estonia & 563 \\
\hline Austria & 562 \\
\hline Slovenia & 549 \\
\hline
\end{tabular}

Areas around parking lots are considered a source of harmful substances from exhaust emissions. Pollutants are emitted by vehicles entering and leaving, as well as when the engine is idling or warming up, which is more typical for the winter period [6]. In addition, parking lot users are exposed to the harmful effects of toxic compounds due to the proximity of the source. It is especially important in closed car parks. The increase in exhaust emissions in closed spaces, such as multi-storey car parks, which are not adequately ventilated, has negative effects on human health [7]. Diseases caused by inhaling car exhaust fumes include: asthma, chronic lung diseases, inflammation of the respiratory tract, cancer, as well as heart and nervous system dis- 
eases. The negative impact of passenger vehicles on the environment makes it important to be limiting the traffic volume, such as by selecting the optimal route [8]. The solutions associated with Intelligent Transport Systems [911] may facilitate the process of parking a vehicle.

The aim of the presented work is to perform a multicriteria analysis of the parking space selection at a shopping mall, focusing on reducing, among others, travel time, pollutant emissions and fuel consumption. In addition, consideration was given to finding the optimal parking space in the process.

\section{Method}

The road tests were performed at a multi-storey car park located at one of the shopping malls in Poznan. The aim of the measurements was to analyze exhaust emissions during trips in individual zones of the building. The research was divided into stages. Each part corresponded to a particular zone of the car park in which the drive test was performed reflecting the regular use of the car park, i.e. ground floor, 1st floor, 2nd floor, exit (Table 2). As the infrastructure of multi-storey car parks is usually quite extensive, and in the analyzed case the entrance to the car park was located in a different place than the exit, the point at the nearest intersection was assumed as the beginning of the measurements including the entrance and the end of emission measurement during the exit from the car park.

Table 2. Description of the conducted test drives

\begin{tabular}{|l|c|}
\hline Test stage & \multicolumn{1}{c|}{ Performed tests } \\
\hline Ground level & $\begin{array}{c}\text { Entering the ground floor of the car park and } \\
\text { searching for a parking space on this level }\end{array}$ \\
\hline Level 1 & $\begin{array}{c}\text { Immediately after entering the parking lot, the } \\
\text { vehicle was directed to the first floor and went on } \\
\text { to search for a parking space on that floor }\end{array}$ \\
\hline Exit & $\begin{array}{c}\text { Immediately after entering the parking lot, the } \\
\text { vehicle was directed to the second floor and went } \\
\text { on to search for a parking space on that floor }\end{array}$ \\
\hline
\end{tabular}

PEMS equipment was used in the tests for measuring exhaust emissions in real operating conditions. A mobile Semtech-DS unit (Fig. 2) was used, which allows to measure and record the concentrations of several gaseous exhaust compounds. The device includes analyzers with which it is possible to measure individual compounds in the exhaust gas. The exhaust gases at a temperature of $191^{\circ} \mathrm{C}$ from the exhaust system first go to the Flame Ionization Detector (FID), which is responsible for measuring the THC concentration. Then the exhaust gas passes through the cooler, where it is cooled to a temperature of $4^{\circ} \mathrm{C}$, and after being cooled, it is directed to the NDUV analyzer where the $\mathrm{NO}_{\mathrm{x}}$ concentration is measured. Then the NDIR analyzer using infrared is responsible for measuring the concentrations of $\mathrm{CO}$ and $\mathrm{CO}_{2}$. The emission rate of individual compounds is obtained through calculations based on data from an exhaust gas flow meter recording the mass flow rate. Additionally, it is possible to connect data from the OBD and the GPS on-board diagnostic system to the results.
The test runs were made in real road traffic conditions with the use of a Skoda PC (Passenger Car) (Fig. 3), powered by a turbocharged spark ignition engine. The test vehicle met the Euro 6 emission standard, which was achieved, among others, by using a dual injection system using direct injection into the cylinder along with a multi-point injection into the intake manifold. The vehicle was equipped with a TWC (Three Way Catalyst) catalytic converter. Table 3 presents the test vehicle's technical parameters.

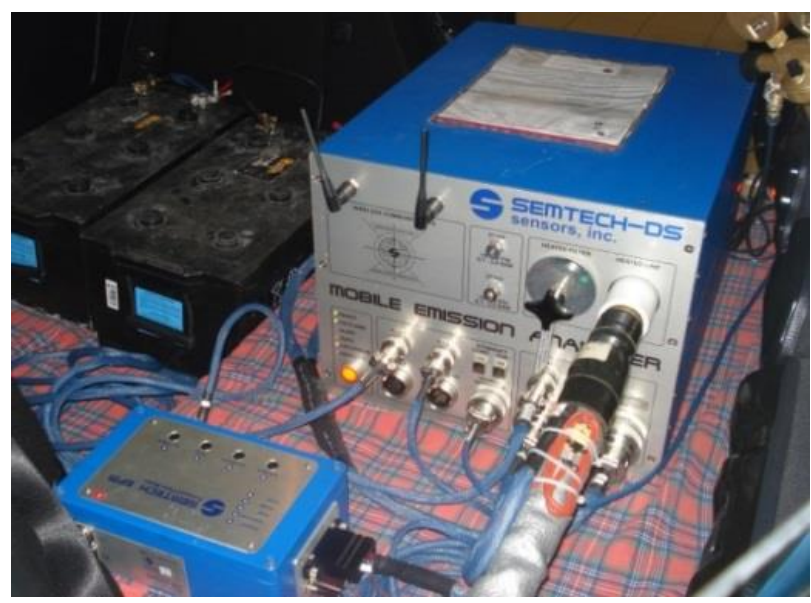

Fig. 2. The SEMTECH-DS exhaust measurement device

Table 3. Basic technical data of the test vehicle

\begin{tabular}{|l|c|c|}
\hline Parameter & Unit & Value \\
\hline Ignition type & - & spark \\
\hline Engine type & - & $\begin{array}{c}4 \text { cylinders/in-line, } \\
4 \text { valves/cylinder }\end{array}$ \\
\hline Displacement & $\mathrm{dm}^{3}$ & 1.8 \\
\hline Nominal power & $\mathrm{kW} / \mathrm{rpm}$ & $132 / 5100-6200$ \\
\hline Nominal torque & $\mathrm{N} \cdot \mathrm{m} / \mathrm{rpm}$ & $250 / 1250-5000$ \\
\hline Equipment & - & $\begin{array}{c}\text { turbocharger, fuel supply } \\
\text { system }- \text { direct gasoline } \\
\text { injection TSI, TWC }\end{array}$ \\
\hline Emission norm & - & Euro 6 \\
\hline
\end{tabular}

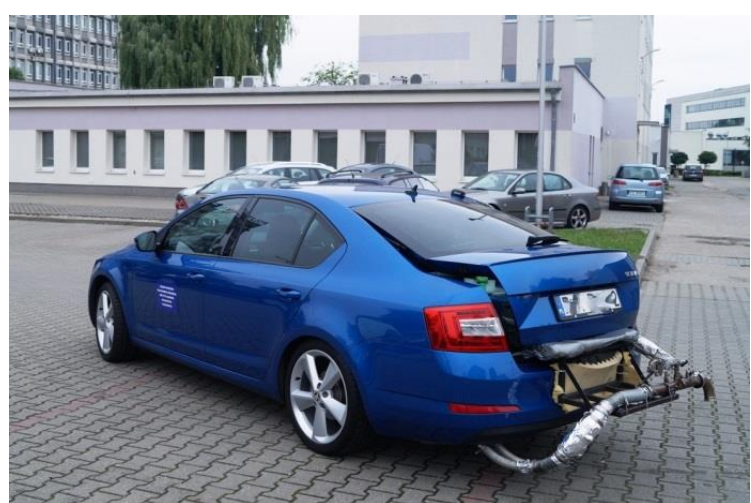

Fig. 3. The test vehicle Skoda Octavia III

\section{Test results}

During the tests carried out in real operating conditions, the operating parameters of the vehicle as well as its location and movement were recorded using the GPS and the vehicle's on-board diagnostic system. Thus the distance 
traveled (Fig. 4) and the average speed of the vehicle (Fig. $5)$ were determined. The routes of individual test drives differed in length. The longest measuring section was recorded for the route marked as the ground floor, and its length was $327.2 \mathrm{~m}$. The remaining routes were noticeably shorter (the passage through level 1 was the shortest). The differences in relation to the longest tested drive section, and the other test routes, were at the level of about $30 \%$ to $60 \%$ and resulted mainly from the building internal layout as well as the time spent searching for a parking space. The mean speed values for the individual routes were very similar to each other and were in the range of approx. $5.4 \mathrm{~km} / \mathrm{h}$ $-10.7 \mathrm{~km} / \mathrm{h}$. The smallest value was recorded during the drive in the ground floor zone, where the speed was about $5.4 \mathrm{~km} / \mathrm{h}$. The reason for the lowest speed values measured in this zone was the high volume of vehicle and pedestrian traffic. This level is the only one meant for entering and exiting the building. The shorter distance and higher mean speeds characterizing the drives along the remaining routes were mainly due to the shorter duration of searching for a parking space on higher storeys of the car park. The drive defined as an exit was characterized only by leaving the parking lot without looking for a parking space, and this was the reason for obtaining the highest mean speed value (at the level of $10.7 \mathrm{~km} / \mathrm{h}$ ).

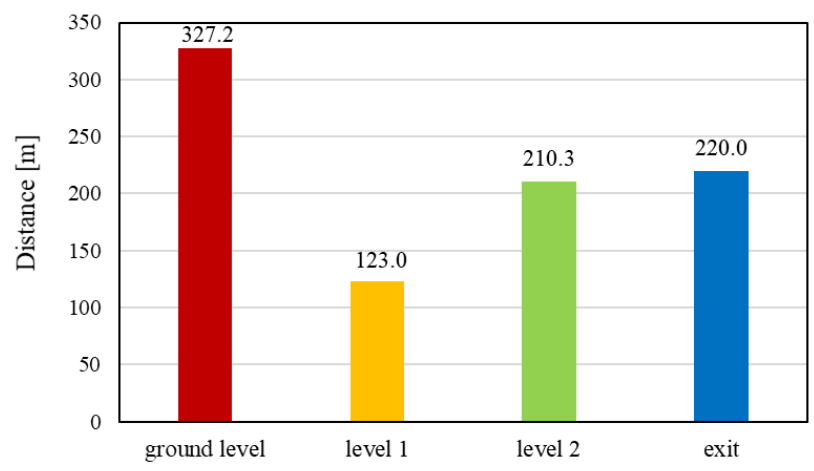

Fig. 4. Comparison of the distance travelled for each test stage

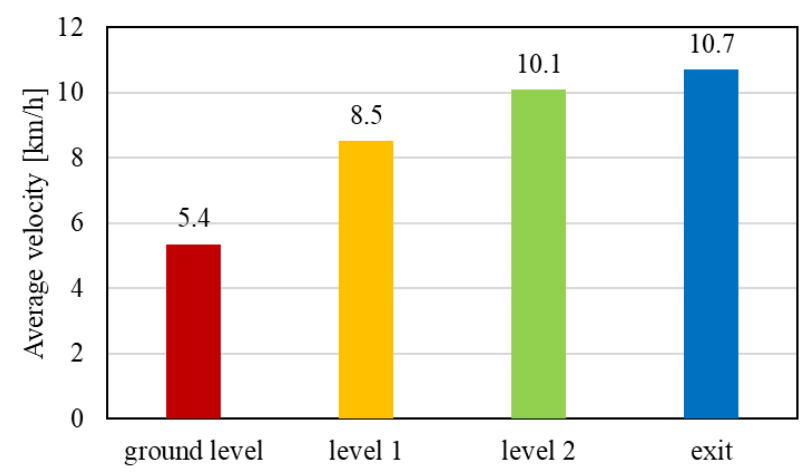

Fig. 5. Comparison of the mean vehicle travel speed for each test stage

The vehicle speed and the emission intensity of the analyzed exhaust components during the trip on the ground floor were shown in Figure 6. During vehicle acceleration the emission intensity of all measured exhaust components increased. This was due to the fact that the individual acceleration maneuvers were all very short-lived - the engine was still operating in transient states while performing them. In addition, the acceleration of the vehicle increases the engine speed and load, which naturally results in a greater emission of exhaust gases emitted by the vehicle engine. This phenomenon may contribute to a greater exhaust emission intensity for individual exhaust gas components, even if the change of thermodynamic parameters in the combustion chamber would contribute to a reduction in the concentration of any exhaust gas component.

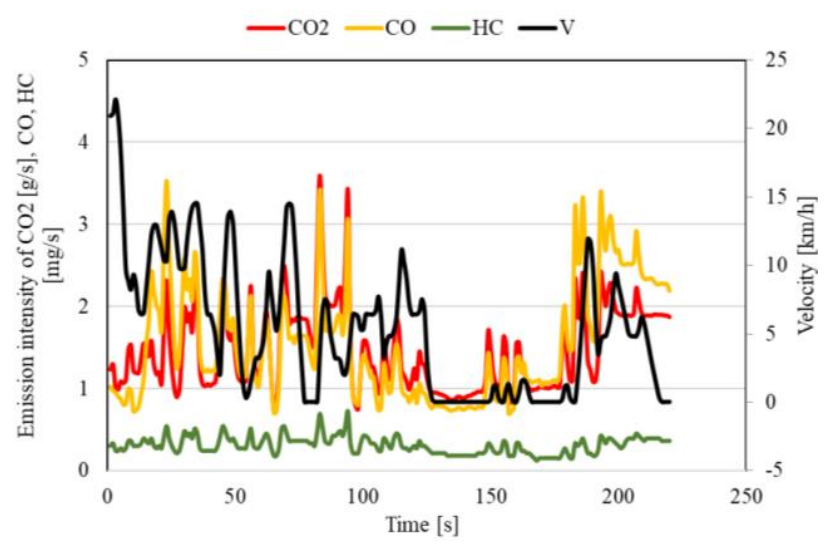

Fig. 6. Vehicle speed along with the $\mathrm{CO}_{2}, \mathrm{CO}$ and $\mathrm{HC}$ emission intensity observed while driving on the ground floor

The $\mathrm{CO}_{2}$ emissions from combustion-powered vehicles are closely related to their fuel consumption. Figure 7 shows the emission of carbon dioxide emitted in individual test drives. Generally, it can be assumed that when looking for a parking spot, $\mathrm{CO}_{2}$ emissions increase with the increasing distance traveled necessary to park the vehicle. However, this relationship was not direct, and the $\mathrm{CO}_{2}$ emission value was also influenced by the nature of the drive. In the ground floor zone, where traffic is greatest, the vehicle would often brake and then start moving again. Accelerating the vehicle, i.e. the sudden change in engine load, requires energy, which is obtained from the fuel. With smooth driving, fuel consumption, and, as a result, $\mathrm{CO}_{2}$ emissions were much lower. The described conditions are most evident for the measurement defined as the descent. This is due to the nature of the drive, which includes the exit from the multi-storey car park, starting from the second floor. Thus, in this case, the vehicle is travelling down slopes from the top to the bottom levels of the car park, and thus the engine is operated at a lower load.

Spark ignition engines are characterized by an increased emission of carbon monoxide compared to compression ignition engines. This is due to the fact that the engine runs on rich mixtures at high loads. The highest emissions CO was characterized by the passage in the ground floor stage, reaching approximately $338 \mathrm{mg}$ (Fig. 8). As mentioned, this zone is characterized by high vehicle traffic intensity and pedestrian movement. This forces constant speed changes that affect the engine load, and thus also the carbon monoxide emissions. The smallest emission of CO (approx. 94 $\mathrm{mg}$ ) was emitted by the vehicle during the test defined as level 1 , which is approximately three and a half times less than in the ground floor stage. 
In addition to carbon dioxide and carbon monoxide, the research was supplemented by measuring the hydrocarbon emissions. During the test drives, the highest emission of these compounds was observed in the ground floor stage tests (almost $70 \mathrm{mg}$, Fig. 9). The smallest $\mathrm{HC}$ emission was measured during a run on level 1 (approx. $5.9 \mathrm{mg}$ ). During the level 2 and down slope driving, the vehicle emitted approx. $27 \mathrm{mg}$ and $17.3 \mathrm{mg} \mathrm{HC}$, respectively, which is still much lower than when travelling through the ground floor.

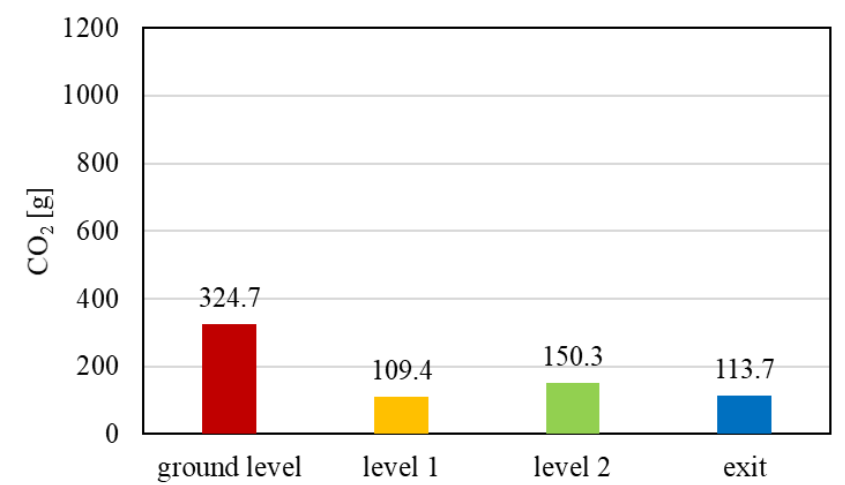

Fig. 7. Comparison of $\mathrm{CO}_{2}$ emissions for each test drive stage

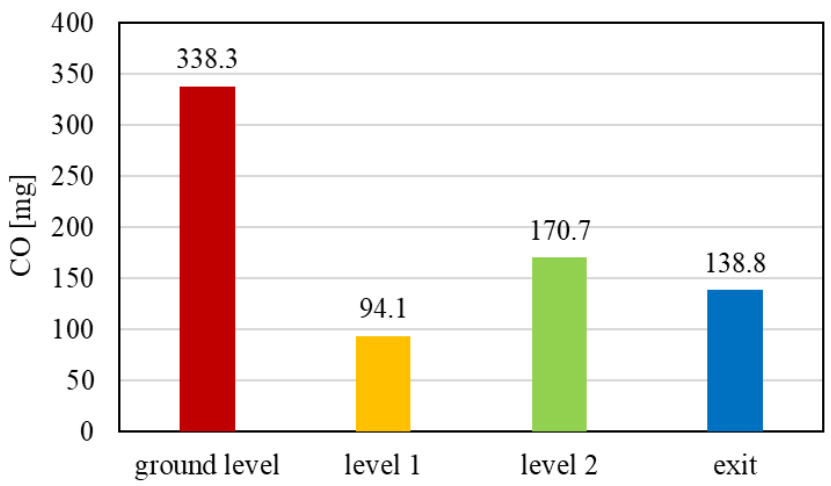

Fig. 8. Comparison of $\mathrm{CO}$ emissions for each test drive stage

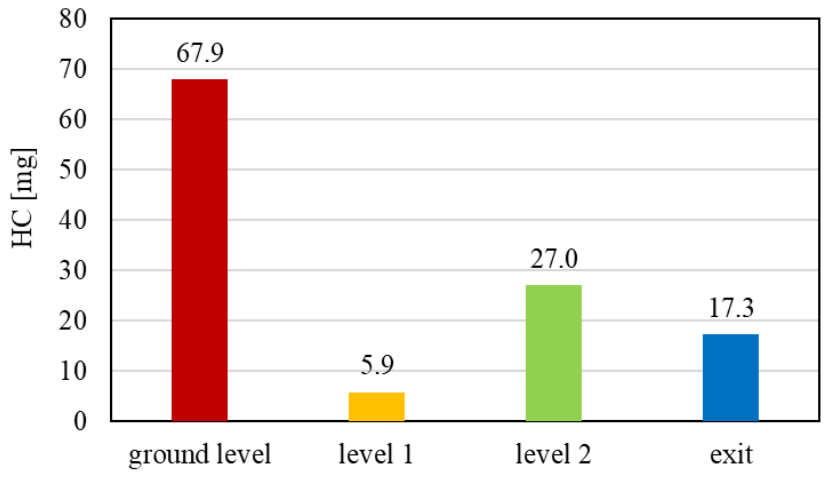

Fig. 9. Comparison of THC emissions for each test drive stage

\section{Results analysis}

In order to fully establish the impact of the parking spot selection method within a multi-storey car park, it is necessary to know the emissions both when entering and leaving the car park. As the conducted research is the Authors' initial approach to the subject of the environmental impact of vehicles using a multi-storey car park, the analyzes of the total emissions (entry and exit) were estimated using the recorded emission results when leaving the second floor of the car park. For this purpose, the recorded exit from the parking lot has been divided into individual fragments (Fig. 10):

I - moving from the parking spot to the exit to the lower level,

II - moving down a level,

III - moving between the exit ramps and leaving the car park,

IV - moving back to the starting point.

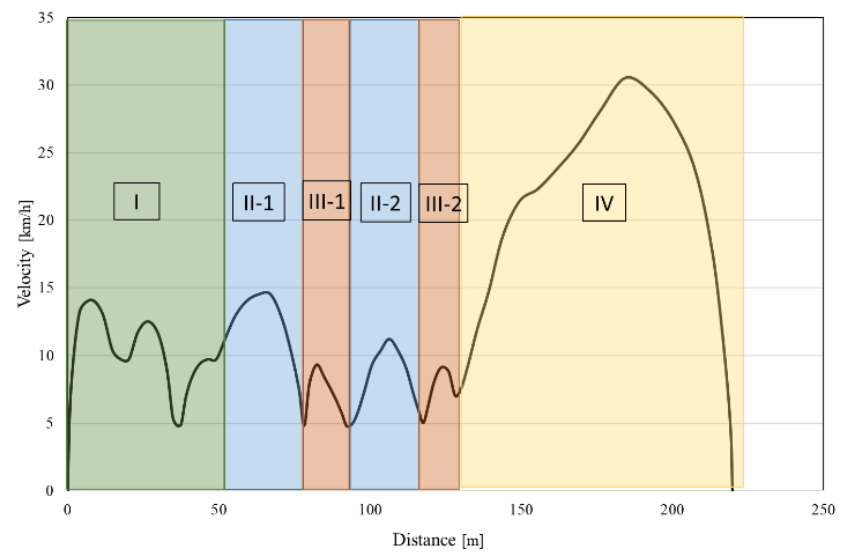

Fig. 10. The velocity in individual stages of leaving the second floor of the analyzed multi-storey car park

When estimating the total emission from the whole drive test within the analyzed car park for entry and exit points, a methodology was adopted where the emission values recorded during the entrance to the car park and the appropriate combination of phases including the exit from the car park were all summed up (Table 4).

Table. 4. The three parking scenarios

\begin{tabular}{|l|l|}
\hline Scenario & \multicolumn{1}{|c|}{ Analyzed data } \\
\hline Ground floor parking & $\begin{array}{l}\text { Moving through the ground level and exiting } \\
\text { the car park (sections: I, III-2 and IV) }\end{array}$ \\
\hline 1st floor parking & $\begin{array}{l}\text { Moving through level 1 level and exiting the } \\
\text { car park (sections: I, II-1, III-2 and IV) }\end{array}$ \\
\hline 2nd floor parking & $\begin{array}{l}\text { Moving through level 2 and exiting the car } \\
\text { park }\end{array}$ \\
\hline
\end{tabular}

As a result of the analyzes in terms of the nature of the drive tests parameters (distance, time, mean travel speed) were shown in Fig. 11. When analyzing the nature of the entire drive through a multi-storey car park, it can be noticed that the greatest distance was traveled by a vehicle parked on the ground floor $(482.5 \mathrm{~m})$. This situation reflects the long-term search for a parking spot in a heavily crowded part of the parking lot - the time between entry and exit was 267 seconds while the test lasted, and the mean vehicle speed was $6.5 \mathrm{~km} / \mathrm{h}$. Parking on the second floor, which means parking in a theoretically more distant place, resulted in travelling a distance of $430 \mathrm{~m}$. This means a reduction of the distance traveled by approx. $52 \mathrm{~m}(-10 \%)$. The travel time decreased by $44 \%$, and the average travel speed was increased by approx. $60 \%$. The shortest distance and the shortest time traveled were both observed for the vehicle when parking on the 1 st floor. 


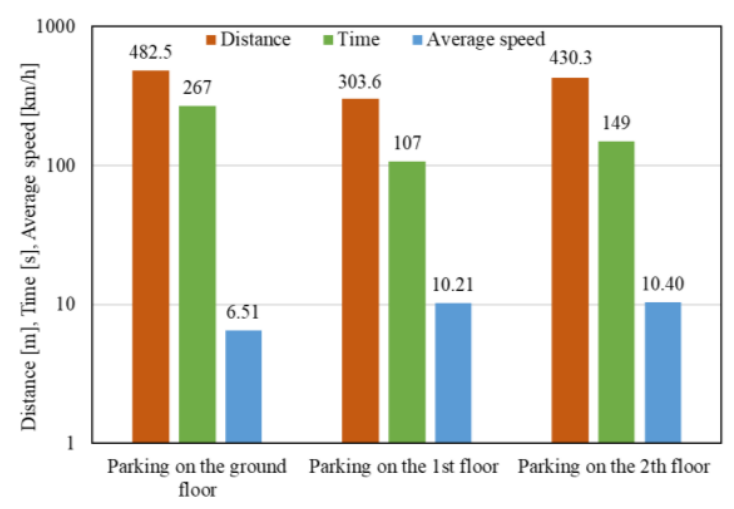

Fig. 11. The distance, time and average speed of the vehicle movement during different parking scenarios in a multi-storey car park

Exhaust emission values for the adopted scenarios of finding a parking spot a multi-storey car park, estimated in accordance with the methodology discussed, including both entry and exit to and from the car park, have been shown in Fig. 12. In the analyzed case, the least favorable, in terms of the total emission of harmful exhaust gases, was parking on the ground floor of a multi-storey car park. During this test drive, the vehicle emitted $405 \mathrm{~g} \mathrm{CO}_{2}$, approx. $436 \mathrm{mg} \mathrm{CO}$ and approx. $81 \mathrm{mg} \mathrm{HC}$. Parking on the $1 \mathrm{st}$ level was found to be the most favorable in terms of total emissions. The emission from a vehicle parking on the 1 st level were lower for each of the analyzed exhaust compounds: $-50 \% \mathrm{CO}_{2}$, $53 \% \mathrm{CO}$ and $-75 \% \mathrm{HC}$ comparing to parking on the ground floor. The emission of compounds when parking on the 2nd floor was greater than when parking on the 1st floor, but these values were still lower than when parking on the ground floor.

Similar relationships can be observed in the field of specific distance emissions (Fig. 13). Despite comparing the emission of compounds to the distance traveled by the test vehicle, parking in the crowded part of the parking lot so parking on the ground floor was characterized by the highest exhaust emission values. In relation to the distance traveled, the lowest $\mathrm{CO}_{2}, \mathrm{CO}$ and $\mathrm{HC}$ emission values have been observed when parking on the 1 st level of the tested multi-storey car park (respectively 48\%, 52\%, 74\% less than when parking on the ground floor) Proportional relations, as in the case of specific distance $\mathrm{CO}_{2}$ emissions, was obtained in the case of the vehicle fuel consumption (Fig. 14).

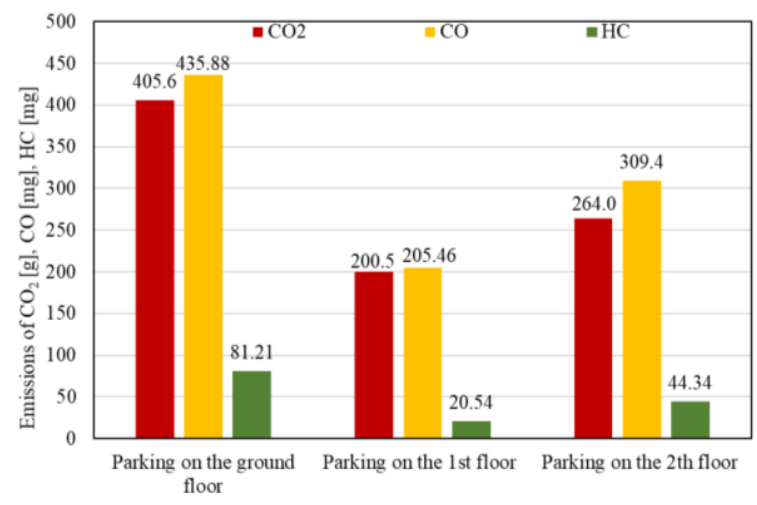

Fig. 12. The total emission of harmful exhaust components in different parking scenarios in a multi-storey car park

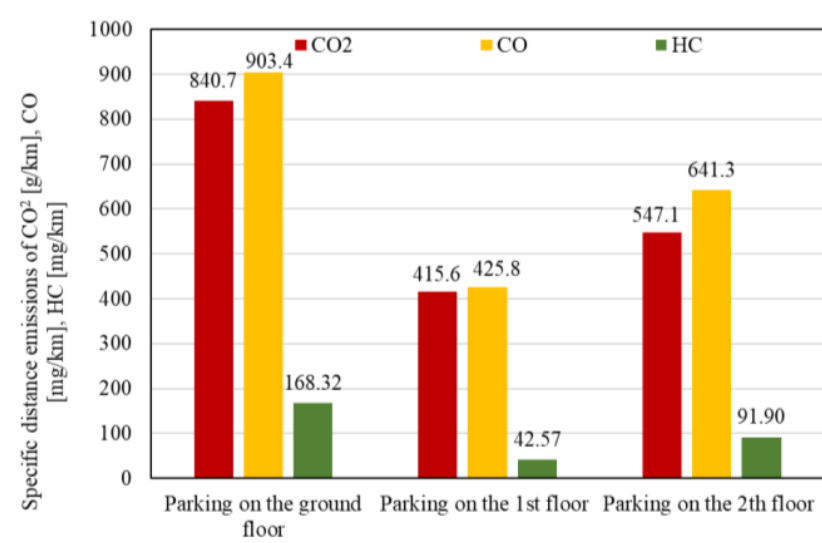

Fig. 13. Specific distance emissions of harmful substances during various parking scenarios in a multi-storey car park

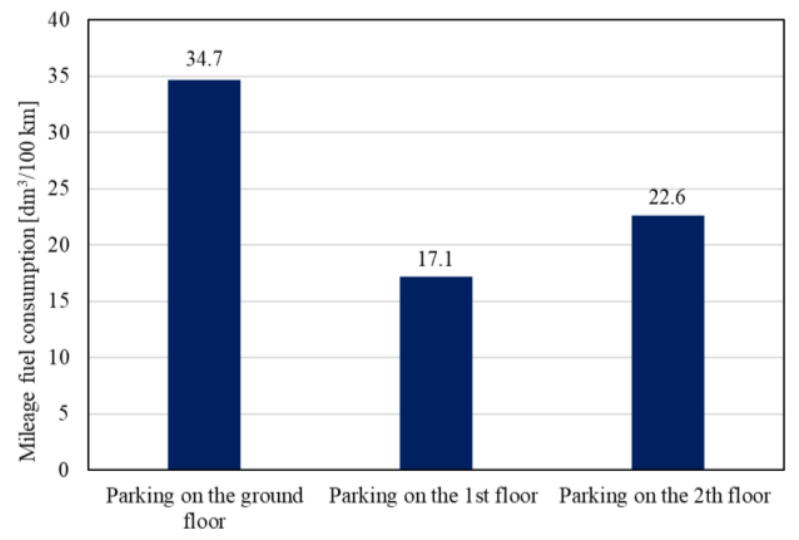

Fig. 14. The operational fuel consumption values during various parking scenarios in a multi-storey car park

\section{Conclusions}

The floor 1 drive stage was characterized by having the shortest distance travelled, while the vehicle covered the longest distance in the ground floor stage. Due to the volume of traffic, finding a parking spot on the ground floor was significantly more time-consuming, and the high level of congestion comes from the desire od people to park right after entering. However, this leads to an increase in the time needed to search for a free spot. This time can be significantly reduced by entering a higher level of the car park, which is not so often chosen by other drivers. According to the obtained results the optimal choice was floor 1 , which was a compromise between congestion (less than on the ground floor) and the length of the access route (shorter than to floor 2). Due to the high volume of traffic, the lowest average speed was observed for the stage on the ground floor, and the highest for the exit drive. The fuelconsumption related $\mathrm{CO}_{2}$ emissions were lowest for the drive at floor 1 and highest on the ground floor. Taking the operating costs and the emission of harmful substances as a criterion (depending, among others, on fuel consumption), the best choice was concluded to be entering the $1^{\text {st }}$ floor to find a spot. Parking on the ground floor, on the other hand, was unfavorable, including due to the $\mathrm{CO}$ and $\mathrm{HC}$ emissions, which then reached the highest value.

The considerations were supplemented with an extended analysis of the test drives. After compiling the three scenarios of route stages within the parking lot, taking into ac- 
count the entrance to and exit from the multi-storey car park next to a shopping mall, it can be concluded that looking for a parking spot on the ground level is the worst choice taking into account all the considered criteria (distance, time, mean speed, specific distance emissions and fuel consumption).

\section{Nomenclature}

$\mathrm{CO}$ carbon monoxide

$\mathrm{CO}_{2}$ carbon dioxide

FID flame ionization detector

GPS global positioning system

NDIR non-dispersive infrared

NDUV non-dispersive ultraviolet
$\mathrm{NO}_{\mathrm{x}} \quad$ nitrogen oxides

OBD on-board diagnostics

PC passenger car

PEMS portable emission measurement dystem

THC total hydrocarbons

TWC three way catalyst

\section{Bibliography}

[1] Climate change consequences. European Commission. ec.europa.eu/clima/change/consequences_en (accessed on 15.07.2020).

[2] Regulation (EC) No 715/2007 of the European Parliament and of the Council of 20 June 2007 on type approval of motor vehicles with respect to emissions from light passenger and commercial vehicles (Euro 5 and Euro 6) and on access to vehicle repair and maintenance information. https://eurlex.europa.eu/legal-

content/EN/ALL/?uri=celex\%3A32007R0715

[3] $\mathrm{CO}_{2}$ emissions from cars: facts and figures. European Parliament.

https://www.europarl.europa.eu/news/en/headlines/priorities /climate-change/20190313STO31218/co2-emissions-fromcars-facts-and-figures-infographics (accessed on 15.07.2020).

[4] Passenger cars in the EU. Eurostat. Statistics Explained. ec.europa.eu/eurostat/statistics-

ex-

plained/index.php?title=Passenger_cars_in_the_EU\&stable= 1\%20\#Highest_share_of_passenger_cars_over_20_years_ol d_in_Poland/ (accessed on 15.07.2020).

[5] TomTom International. www.tomtom.com/en_gb/trafficindex/poznan-traffic/ (accessed on 15.07.2020).

Maciej Andrzejewski, DEng. - Łukasiewicz Research Network - Rail Vehicle Institute "TABOR", Poland.

e-mail:

maciej.andrzejewski@tabor.lukasiewicz.gov.pl

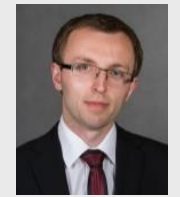

Mateusz Nowak, DEng. - Faculty of civil and Transport Engineering, Poznan University of Technology.

e-mail: mateusz.s.nowak@put.poznan.pl.pl
[6] STEINBERGA, I., KLEPERIS, J. Urban air pollution: input car parking places. Urban Transport X. 2004, 75, https://doi.org/10.2495/UT040831

[7] DEMIR, A. Innovation and entrepreneurship investigation of air quality in the underground and aboveground multistorey car parks in terms of exhaust emissions. Procedia Social and Behavioral Sciences. 2015, 195, 2601-2611. https://doi.org/10.1016/j.sbspro.2015.06.461

[8] MERKISZ, J., PIELECHA, J., FUĆ, P. et al. Assessment of vehicle emission indicators for diverse urban microinfrastructure. Combustion Engines. 2013, 154(3), 787-793.

[9] ELSONBATY, A.A., SHAMS, M. The smart parking management system. International Journal of Computer Science \& Information Technology. 2020, 12(4), 55-66. https://doi.org/10.5121/ijcsit.2020.12405

[10] ALAM, M., MORONI, D., PIERI, G. et al. Real-time smart parking systems integration in distributed ITS for smart cities. Journal of Advanced Transportation. 2018, 2018. https://doi.org/10.1155/2018/1485652

[11] GUERRERO-IBÁÑEZ, J., ZEADALLY, S., CONTRERAS-CASTILLO, J. Sensor technologies for intelligent transportation systems. Sensors. 2018, 18(4), 1212. https://doi.org/10.3390/s18041212

Aleksandra Woch, MEng. - Łukasiewicz Research
Network - Rail Vehicle Institute "TABOR", Poland.

Network - Rail Vehicle Institute "TABOR", Poland.
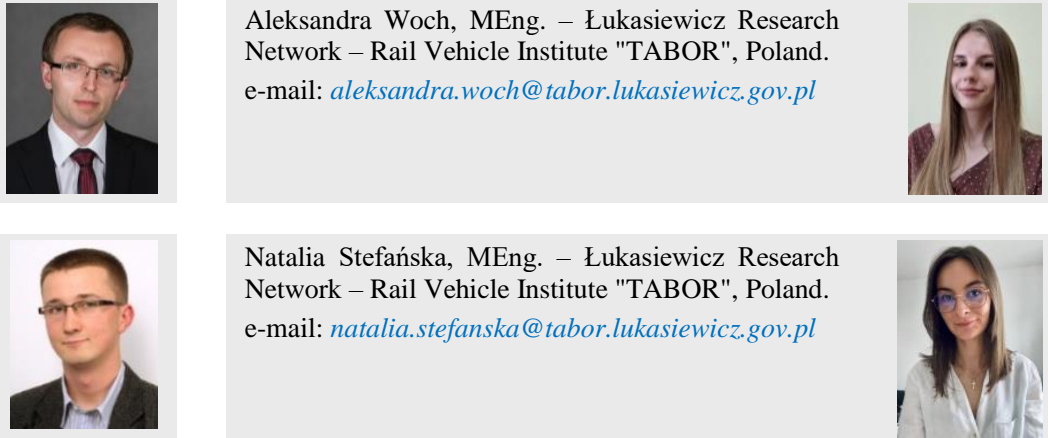

Natalia Stefańska, MEng. - Łukasiewicz Research Network - Rail Vehicle Institute "TABOR", Poland. e-mail: natalia.stefanska@tabor.lukasiewicz.gov.pl 